\section{Reconsidering the Trade-Creating Effects of a Currency Union}

\author{
Michael R. Pakko and Howard J. Wall
}

C ountries select particular exchange rate arrangements for a variety of reasons. For example, the ability to conduct an independent monetary policy is often cited as the main advantage of having a floating exchange rate regime. Conversely, countries sometimes tie their exchange rate to that of a larger country-foregoing the ability to conduct independent monetary policies-to benefit from the relative stability of the foreign currency. This is the rationale for several Latin American countries that have recently adopted or are considering policies of dollarization.

A more prevalent rationale for adopting fixed exchange rates or even common-currency arrangements, however, is the notion that exchange rate volatility introduces uncertainty into cross-border transactions, reducing the volume of trade that would otherwise take place. Indeed, this argument played a key role in the decision of the European Union to embark upon plans for introducing the euro. As described in an early EU Green Paper on the subject:

An exchange rate adjustment, even a moderate one, may substantially alter the balance of a contract between two European firms and at the same time affect the relative wealth of citizens and the purchasing power of consumers. Only a single currency covering the largest possible number of Member States can shelter firms and individuals from these disruptions. (European Commission, 1995)

Despite the firmly held convictions of many economists and policymakers that exchange rate volatility and uncertainty dampens trade, there has

Michael R. Pakko is a senior economist and Howard J. Wall is a research officer at the Federal Reserve Bank of St. Louis. The authors thank Andrew Rose and Cheng Hsiao for their comments and suggestions. Much of this research was done while Wall was a visiting scholar at the Institute for Monetary and Economic Studies at the Bank of Japan, whose hospitality and resources are greatly appreciated. Rachel J Mandal provided research assistance. been little empirical evidence to support this premise. ${ }^{1}$ Studies often find that the effect is of the wrong sign (Brada and Mendez, 1988), statistically insignificant (Belanger, Gutierrez, and Raynauld, 1992), or at best very weak (Frankel and Wei, 1993). Recent theoretical work also suggests that the association may not hold in the context of general equilibrium or for all forms of risk aversion (Bacchetta and van Wincoop, 2000, and De Grauwe, 1988).

In a drastic departure from past empirical studies that fail to find a significant link between exchange rate stability and trade, a recent set of papers by Andrew Rose and his colleagues find extremely large positive effects of common currencies on the volume of trade. The most dramatic, and widely cited, of his findings is that "two countries sharing the same currency trade three times as much as they would with different currencies" (Rose, 2000, p.7).

In related work, Rose and Engel (2000) found similarly large trade-creating effects by comparing the extent of integration between countries with common currencies to that of regions within the same country. Other work (Frankel and Rose, 2000) has combined estimates of the trade-creating effects of common currencies with evidence of a link between trade and growth, concluding that some countries could increase their per capita income by 20 percent over 20 years by dollarizing or adopting the euro. Most recently, Glick and Rose (2001) use a much larger data set and find that a common currency doubles trade.

Rose's estimates of the trade-creating effects of adopting common currencies are obtained using a "gravity model" in which bilateral trade is a function of the relative economic size and distance between two trading partners. In general, these simple factors can explain a great deal of observed trade patterns, and gravity models are generally deemed to be empirically successful. Rose's model also includes several variables that are intended to capture trading partners' cultural and historical links and membership in regional trading blocs. The key feature of Rose's gravity model is the inclusion of two monetary variables: a dummy variable to indicate whether trading partners use the same currency and a measure of the volatility of the bilateral exchange rate.

In this paper, we re-examine the trade-creating effects of common currencies, replacing Rose's equation with a more general functional form.

\footnotetext{
1 See Côté (1994) for a comprehensive survey.
} 
Specifically, rather than controlling for cultural, geographic, and historical factors by introducing particular variables, we allow for general fixed effects that are specific to each trading pair. Estimating this modified form of the model, we find that the trade-creating effects of common currencies found by Rose disappear. This suggests a tenuousness in the findings that should give one pause before concluding that the potential gains from adopting common currencies are as great as Rose indicates.

\section{COMPETING GRAVITY MODELS}

To obtain his benchmark results, Rose uses ordinary least squares (OLS) to estimate an equation that includes the typical gravity-model variables, as well as a list of dummy variables intended to control for common historical and cultural influences that might influence trade volumes. Specifically, he estimates the following equation:

(1)

$$
\begin{aligned}
& \ln \left(X_{i j t}\right)= \\
& \quad \beta_{0}+\beta_{1} \ln \left(Y_{i t} Y_{j t}\right)+\beta_{2} \ln \left(y_{i t} y_{j t}\right)+\theta_{1} \ln D_{i j}+\theta_{2} \operatorname{Cont}_{i j} \\
& \quad+\lambda_{1} L \operatorname{lang}_{i j}+\lambda_{2} \operatorname{ComNat}_{i j}+\lambda_{3} \operatorname{ComCol}_{i j}+\lambda_{4} \operatorname{Colony}_{i j} \\
& \quad+\omega F T A_{i j t}+\tau T^{\prime}{ }_{i j t}+\gamma C C_{i j t}+\delta V\left(e_{i j t}\right)+\varepsilon_{i j t},
\end{aligned}
$$

where $X_{i j t}$ is the total real trade of country $i$ with country $j$ in year $t$. The usual gravity variables are $Y_{i t}$ and $Y_{j t}$, the gross domestic products (GDPs) of $i$ and $j ; y_{i t}$ and $y_{j t}$, their real per capita GDPs; $D_{i j}$, the great-circle distance between them; and Cont $t_{i j}$, a dummy variable to indicate whether they are contiguous. The four time-invariant cultural and historical dummy variables take the value of 1 when the partners (i) have a common first language, Lang $_{i j}$; (ii) are part of the same nation (for example, if they are both French overseas departments), ComNat ${ }_{i j}$; (iii) were colonies of the same colonizer after 1945, $\mathrm{ComCol}_{i j}$; or (iv) if one was a colony of the other, Colony $i j$. To control for the trade-creating effects of regional integration, the dummy $F T A_{i j t}$ is equal to 1 when the partners are members of the same free trade area or other form of regional integration regime. The model also includes a vector of time dummies, $T_{i j t}$.

The variables of most present interest are the two monetary variables: $C C_{i j t}$, a dummy that is equal to 1 if $i$ and $j$ use the same currency; and $V\left(e_{i j t}\right)$, which is a measure of the volatility of the exchange rate between the currencies of $i$ and $j$. The latter is the standard deviation of the first difference in the $\log$ of the bilateral exchange rate between $i$ and $j$ for the five years prior to the year of the observation.

We propose an alternative, more general specification of equation (1) that uses trading pairspecific fixed effects to control for time-invariant geographic, cultural, and historical factors. Rather than controlling for these factors with a list of particular variables, as Rose does, we use fixed effects that are specific to each of the trading pairs (see Bayoumi and Eichengreen, 1997, and Cheng and Wall, 2001).

The general advantage of this fixed-effects approach is that it avoids estimation bias that can arise because of misspecified or omitted timeinvariant factors that are correlated with bilateral trade and some right-hand-side variables. For example, there may be some unobserved (or uncontrolledfor) factors that are responsible for both the level of trade between two countries and whether or not they have a common currency. If so, then any estimation that does not control for such factors would mistakenly attribute a correlation between trade and a common currency to a direct link between the two characteristics, rather than with the unobserved attributes. In the context of the present question, the fixed-effects approach has the additional advantages of not having to use distance to measure relative trading costs and of allowing for a better empirical representation of the dynamic link between common currencies and trade.

We use least squares with dummy variables (LSDV) to estimate the equation

(2)

$$
\begin{aligned}
\ln \left(X_{i j t}\right) & = \\
& \beta_{0}+\beta_{i j}+\beta_{1} \ln \left(Y_{i t} Y_{j t}\right)+\beta_{2} \ln \left(y_{i t} y_{j t}\right) \\
& +\omega F T A_{i j t}+\tau T^{\prime}{ }_{i j t}+\gamma C C_{i j t}+\delta V\left(e_{i j t}\right)+\mu_{i j t} .
\end{aligned}
$$

Note that $\beta_{i j}$, the trading pair-specific component of the intercept, incorporates all of the time-invariant factors that are included separately in specification (1); these include the distance and contiguity variables, as well as the time-invariant cultural and historical factors included in (1). More importantly, this fixed-effects term also controls for factors that are not included in (1). In other words, rather than explicitly controlling for the factors Lang $_{i j}$, ComNat $i j$, ComCol $_{i j}$, and Colony ${ }_{i j}$ - and only those factors we allow the data to identify common characteristics that influence the volume of trade between two countries. 


\section{RESTRICTED FIXED EFFECTS}

The fixed-effects approach that we use is the most general that has been applied to the question of common currencies. ${ }^{1}$ It assumes that, for each pair of countries, there is likely to be a unique set of reasons for trade volume to differ from the average. Unlike standard pooled cross-section estimation, it allows for the possibility that cultural or historical factors can explain why trade between the United States and the United Kingdom is so much greater than trade between, say, the United States and France. Although fixed effects have been applied to gravity models only recently, other fixed-effects specifications have appeared in the literature.

Mátyás (1997) and Egger (2000) specify two fixed effects for each country, one for when it is an exporter and one for when it is an importer. Applying this to equation (2) yields

(3)

$$
\begin{aligned}
& \ln \left(X_{i j t}\right)= \\
& \beta_{0}+\theta_{i}+\rho_{j}+\beta_{1} \ln \left(Y_{i t} Y_{j t}\right) \\
& +\beta_{2} \ln \left(y_{i t} y_{j t}\right)+\theta_{1} \ln D_{i j}+\theta_{2} \operatorname{Cont}_{i j} \\
& +\lambda_{1} \operatorname{Lang}_{i j}+\lambda_{2} \operatorname{ComNat}_{i j}+\lambda_{3} \operatorname{ComCol}_{i j}+\lambda_{4} \operatorname{Colony}_{i j} \\
& +\omega F T A_{i j t}+\tau T^{\prime}{ }_{i j t}+\gamma C C_{i j t}+\delta V\left(e_{i j t}\right)+\varepsilon_{i j t},
\end{aligned}
$$

where $\theta_{i}$ is the fixed effect for $i$ when it is an exporter and $\rho_{j}$ is the fixed effect for $j$ when it is an importer. Because distance, contiguity, and language are not perfectly collinear with the fixed effects, unlike in (2), they need not be dropped from the regression. Note that equation (3) can be obtained by imposing the arbitrary restriction on (2) that $\beta_{i j}=\theta_{i}+\rho_{j}+Z_{i j}$, where $Z_{i j} \equiv \theta_{1} \ln D_{i j}+$ $\theta_{2}$ Cont $_{i j}+\lambda_{1}$ Lang $_{i j}+\lambda_{2}$ ComNat $_{i j}+\lambda_{3}$ ComCol $_{i j}+$ $\lambda_{4}$ Colony $_{i j}$. Because this also means that $\beta_{i k}=\theta_{i}+$ $\rho_{k}+Z_{i k}$, these restrictions on the trading-pair fixed effects imply the cross-pair restriction that $\beta_{i j}-\beta_{i k}=\rho_{j}-\rho_{k}+Z_{i j}-Z_{i k}$.
In this specification, the United States has two fixed effects: one to control for the factors that make its exports differ from the average and another to do the same for its imports. The trading-pair effect for U.S. exports to the United Kingdom is the sum of the fixed effect for U.S. exports and the fixed effect for U.K. imports. Similarly, for U.S. exports to France, the tradingpair effect is the sum of the fixed effect for U.S. exports and the fixed effect for French imports. Because the fixed effect for U.S. exports is part of both of these trading-pair effects, this specification imposes the arbitrary restriction on how the two trading-pair effects are related to each other and to all other trading-pair effects. As shown by Cheng and Wall (2001), these arbitrary restrictions result in poor in-sample predictions.

A more restricted fixed-effects specification than (3) was employed in Rose and van Wincoop (2001) and in a working paper version of Rose (2000) ( < haas.berkeley.edu/ arose/ > ). In these papers, there is one fixed effect for each country, regardless of whether the country is the importer or the exporter, i.e., $\theta_{j}=\rho_{j}$. Applying this restriction, (3) becomes

$$
\begin{aligned}
& \ln \left(X_{i j t}\right)= \\
& \beta_{0}+\theta_{i}+\theta_{j}+\beta_{1} \ln \left(Y_{i t} Y_{j t}\right) \\
& +\beta_{2} \ln \left(y_{i t} y_{j t}\right)+\theta_{1} \ln D_{i j}+\theta_{2} \operatorname{Cont}_{i j} \\
& +\lambda_{1} \text { Lang }_{i j}+\lambda_{2} \operatorname{ComNat}_{i j}+\lambda_{3} \operatorname{ComCol}_{i j}+\lambda_{4} \text { Colony }_{i j} \\
& +\omega^{\prime} \operatorname{CA}_{i j t}+\tau T^{\prime}{ }_{i j t}+\gamma C C_{i j t}+\delta V\left(e_{i j t}\right)+\varepsilon_{i j t} .
\end{aligned}
$$

Using this specification of fixed effects, Rose found that a common currency led countries to more than double their bilateral trade.

\footnotetext{
1 See Cheng and Wall (2001) for a discussion of the various fixedeffects specifications used in gravity models.
}

In equation (2), the trading-pair fixed effect is estimated using a separate dummy variable for each trading pair in the data set, so that we need at least two observations of each pair. Note also that we refer to our fixed effects as "general" so as to differentiate them from the restricted fixed effects that have been used in other gravity models in the liter- ature. As we demonstrate in the insert, these specifications are special cases of (2) in that they can be obtained by imposing arbitrary restrictions on the general trading-pair effects.

The main benefit of the fixed-effects approach is that it addresses the possibility of omitted-variables bias by controlling for all factors that are fixed over 
the sample period, not only those included in the estimation. Because the time-invariant factors that these variables are meant to proxy for are often difficult to measure or are unobservable, it is difficult (if not impossible) to include enough variables to account for all of the important factors.

The list of variables included by Rose is as exhaustive as in any gravity model, ${ }^{2}$ yet there is no variable, for example, that captures the unique historical relationships between the United States and Panama or the United States and Liberia. These three countries all use the U.S. dollar; and there are obvious historical reasons why they would (i) be more likely than others to share a currency and (ii) trade more than would be otherwise predicted. Because the model does not control for factors such as these, which are correlated with both trade and the likelihood of sharing a currency, it cannot help but provide biased estimates. It is not feasible to create variables that capture the unique historical relationships between these countries or, for that matter, between any pair of countries. One cannot create variables to control for every pair-specific factor in the universe of trading pairs. ${ }^{3}$ The only sensible solution is to include a dummy variable for each pair that indicates trade between all pairs of trading partners, i.e., to create trading pair-specific fixed effects.

Fixed-effects estimation also addresses the possible problem of misspecification created by the distance variable, which is meant to reflect the relative costs of trading. However, distance is a notoriously poor measure of such costs (Plane, 1984), and examples of why this is so come readily to mind. First, the distance between single points within two countries (usually the national capitals or, as in the present case, the geographic centers) can be a poor indicator of the trading distance between people spread across millions of points within the countries. Second, even without this problem, in terms of trading costs, distance across land is not the same as distance across an ocean. And third, distance across relatively undeveloped countries is not the same as distance across developed ones. The distance between Italy and Spain is only slightly greater than that between Algeria and Niger, but it is difficult to believe that trading costs are lower for the latter pair. The misspecification of trading costs that distance introduces will bias empirical results because the error that it introduces will likely be correlated with one or more of the other right-hand-side variables, as well as with the level of bilateral trade.

The most important consideration in the present context is that fixed-effects estimation allows us to get much better estimates of the dynamic relationship between trade and common currencies. When considering the question of a causal link between adoption of a common currency and increased trade, an obvious approach would be an examination of bilateral trade time series, including both preand post-union observations. However, a relative lack of observations with typical time series makes this impractical for drawing any strong conclusions. A feasible alternative pools the data both crosssectionally and over time, which can be used to estimate a simple gravity model.

One approach is to estimate a model such as the one specified in (1), controlling for as many of the time-invariant factors as possible and hoping that the estimates are not biased because one or more time-invariant factors are excluded or misspecified. The alternative that we propose captures the dynamic link between common currencies and trade by taking advantage of the fact that LSDV estimation is econometrically identical to OLS estimation of differences over time (see Hsiao, 1986, or Greene, 1999). Thus, by controlling for all timeinvariant effects, our estimates should tell us the changes in trade that occurred alongside changes in common-currency status. Unfortunately, given the data set, which has very few observations for which there is a change in common-currency status over the sample period, this approach is not ideal. ${ }^{4}$ Nonetheless, as we demonstrate, it is sufficient for identifying the source of Rose's result, as well as demonstrating its fragility: our empirical estimates suggest the possibility that a common currency may lead to significant reductions in trade.

\section{THE DATA}

Rose's data set-which is available on his Web site < haas.berkeley.edu/ arose/ > - begins with

\footnotetext{
2 In addition to the variables in equation (1), in other specifications Rose includes dummies to indicate whether trading partners are landlocked, are islands, or share the same head of state.

3 For these three countries you could create two dummy variables: one for when the trading pair includes a country that built a canal through the other and another for when one was established by freed slaves from the other.

4 Of the nearly 23,000 observations in the data set Rose used for his benchmark estimate, only 7 have a change in common-currency status.
} 
33,903 observations of bilateral trade between various combinations of 186 countries, dependencies, territories, overseas departments, and other political units for the years 1970, 1975, 1980, 1985, and 1990. Of these observations, 330 are of trade between trading partners that use the same currency. ${ }^{5}$ After eliminating the observations with incomplete data, Rose obtains his benchmark estimates with a pooled cross-section of 22,948 observations, 252 of which are of trade between countries that use the same currency. ${ }^{6}$

Our selection criteria are slightly more stringent than this because we need at least two observations for each pair of trading partners. After eliminating the observations that do not meet this additional criterion, we are left with 21,758 bilateral trade observations of 5,541 trading pairs, with 212 observations of trade between pairs that use the same currency.

One criticism of fixed-effects models is that their estimates reflect short-run relationships of a length defined by the time interval between observations, not the long-run relationships that pooled cross-sections are intended to reveal. In the present context, this view is of limited relevance because the long run, the period over which no factors related to trade are fixed, is a length of time that is of no interest to policymakers or anyone else. The relevant factors-distance, historical relationships, cultural links, etc.- are not likely to become variable at any time in the foreseeable future. Nevertheless, because the five-year interval in Rose's data set may be too short for the affected economies to adjust completely to adoption of a common currency, we also estimate our model using 10- and 20-year intervals.

Our second data set is a subset of the original data that uses observations for 1970, 1980, and 1990 only. After eliminating those trading pairs with only one observation in these three years, there are 11,520 observations of 4,392 pairs remaining, with 112 observations of trade between countries using the same currency. A third data set uses only data from 1970 and 1990, leaving 5,728 observations of 2,864 trading pairs, with only 35 observations of trade between trading partners using the same currency.

Although the first two data sets have roughly the same percentage of observations for which the partners use the same currency (just under 1 percent), the third one has a much smaller percentage (about 0.6 percent). Sample-selection bias therefore becomes a potential problem for the third data set: The country pairs for which data are less likely to be complete tend to be the poorer ones, and, as Rose points out, a disproportionate number of countries using common currencies are relatively poor.

\section{THE EMPIRICAL RESULTS}

Table 1 summarizes the regression results for the pooled cross-section and fixed-effects models for the three data sets. The results for the pooled cross-section model with five-year intervals are nearly identical to Rose's benchmark results, which were obtained with about 1,200 more observations. As with Rose's benchmark, our estimated effect of regional integration suggests that two members of such a regime trade about 2.5 times $\left(e^{0.91}=2.5\right)$ what two countries not in the same regime woulda huge effect that strains credulity. However, because membership in a regional integration regime might be correlated with missing or unobserved cultural or historical factors, this number likely suffers from the same estimation problems that we believe exist for the effects of a common currency (see Cheng and Wall, 2001). We also find, as did Rose, that countries with a common currency trade more than three times as much as they would if they had different currencies $\left(e^{1.173}=3.2\right)$.

The results of our estimation of the gravity model with trading-pair fixed effects and the same data with five-year intervals are dramatically different from the results for the pooled cross-section model. The estimated coefficient on the regional integration dummy shrinks to a statistically insignificant 0.08 percent. The estimated effect of a common currency indicates that two countries sharing the same currency trade only 69 percent $\left(e^{-0.378}=0.69\right)$ of what they would trade if they had different currencies, although this trade-reducing effect is not significantly different from zero statistically. Also, the estimated coefficient on exchange rate volatility shrinks to about one third of what the pooled crosssection model produced. In short, the startlingly large estimates of the effects of regional integration and common currencies produced by Rose's benchmark model disappear when trading-pair fixed effects are used to model time-invariant factors.

5 See Rose (2000) for a complete description of the data set.

6 He also estimated each year separately, finding little difference between the single-year cross-section and pooled cross-section results. 
Regression Results: Dependent Variable $=\log$ of Bilateral Exports

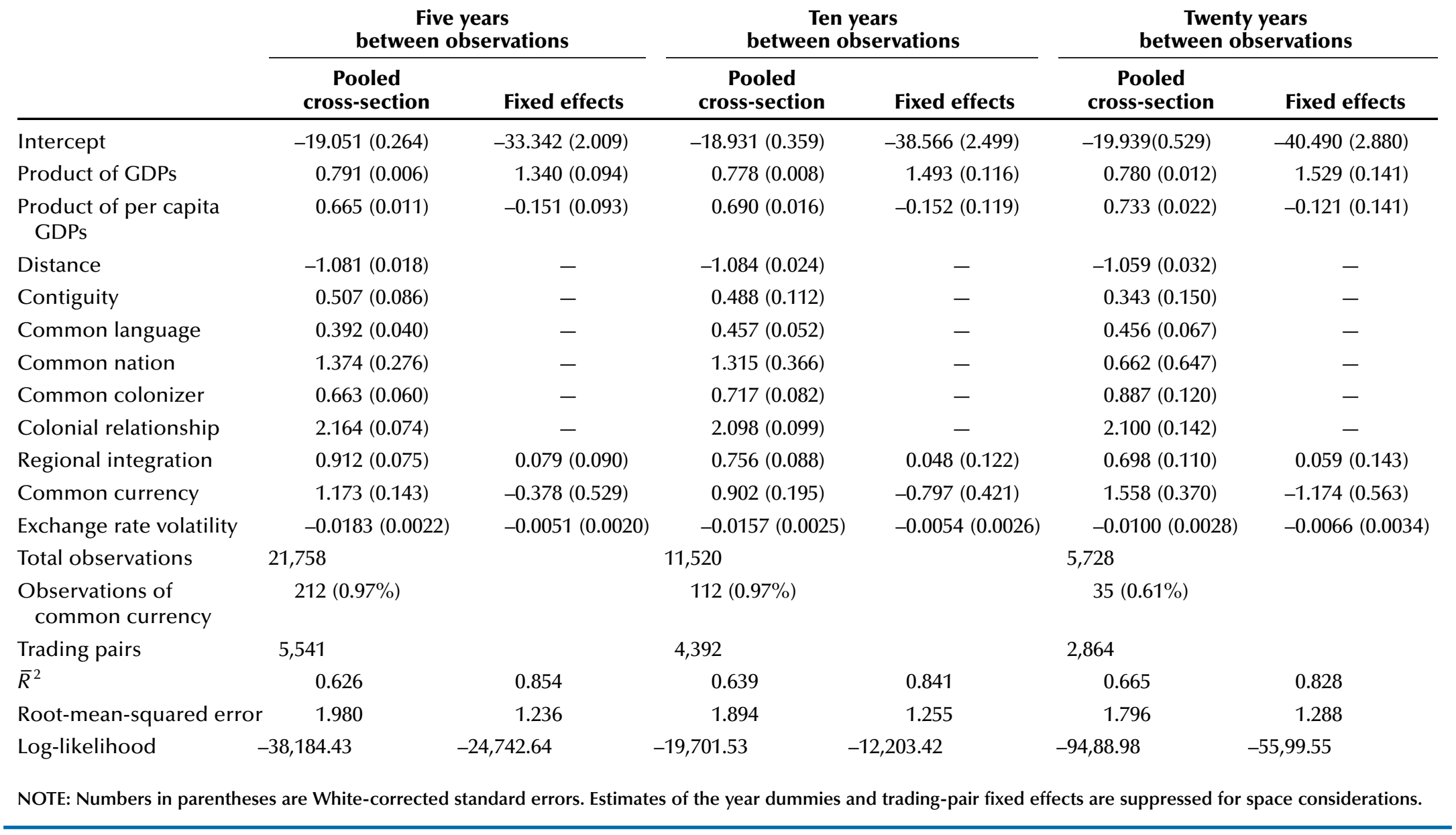


Independently, Rose (2001) obtains these same results using the general fixed-effects model. However, he rejects the findings on the grounds that the statistical insignificance of the common-currency dummy is due to a small number of switches in common-currency status. While it may well be true that the statistical insignificance of the commoncurrency dummy should not be taken to mean that the effect is not positive, this misses the point. A comparison of the two sets of results suggests that pooled cross-section estimates are not reliable because they are biased by the exclusion or mismeasurement of trading pair-specific variables. This is evident in the dramatically different coefficients on the GDP and per capita GDP variables that are found when using the two methods. In other words, the restrictions necessary to obtain the pooled cross-section specification from the fixed-effects specification are rejected, indicating that the fixed-effects specification is preferred. 7,8

The difference between the two methods in their estimates of the trade-creating effect of a common currency is a separate issue. The proper conclusion to draw is that, when the statistically preferred fixed-effects specification is used, there is no statistically significant evidence of large trade effects (positive or negative). Although this means that Rose's results cannot be supported statistically, the small number of switches precludes us from saying much about the effects of common currencies on trade, although the tripling of trade found by Rose is well outside of a 95 percent confidence interval. ${ }^{9}$

As discussed above, the use of data with five-year intervals might be misleading because five years might not be a long enough period for the common currency to have its full trade-creating effect. Our results using data with 10- and 20-year intervals between observations, however, indicate that, if anything, the longer time interval magnifies the tradereducing effects of a common currency. Using the data set with 10-year intervals, we find that countries using the same currency traded only 45 percent $\left(e^{-0.797}=0.45\right)$ of what they would if they had differ ent currencies, an effect that is significantly different from zero at the 6 percent level. And finally, using the data set with 20-year intervals, we find that countries using the same currency traded only 31 percent of what they would if they had different currencies, an effect that is significant at the 4 percent level. Remarkably, we find that the tradereducing effects in this data set are so consistent that the coefficients on the common-currency dummies are statistically significant despite there being so few switches into or out of common currencies.

\section{OTHER RESULTS}

Our results, although statistically persuasive, indicate only the source of Rose's findings with his original data set and are not necessarily useful for making out-of-sample predictions of the effects of a common currency. Using a new data set, Glick and Rose (2001) compare results obtained with pooled cross-estimation with those obtained with a general fixed-effects specification, just as we have done. Their data set has yearly observations of 230 countries from 1948 through 1997, with many more observations of switches into and out of common currencies; although, as in Rose's original data set, only about 1 percent of the sample covers country pairs with a common currency. Their pooled crosssection estimation using yearly observations indicates that a common currency leads to a quadrupling of trade, whereas their fixed-effects estimation indicates that trade will be doubled. Further, they find that this trade-creating effect is large even when longer intervals are used, which is in contrast to our results. They conclude that the fixed-effects estimation shows that the effect of a common currency on trade "is economically large, statistically significant, and seems insensitive to a number of perturbations in...methodology."

Rather than closing the book on the issue, these results actually point to the general sensitivity of the empirical approach. This is because the two sets of results, ours and those of Rose and Glick, were obtained with two equally reasonable data sets that nonetheless differ a great deal in their handling of common currencies. Many of the country pairs noted to share a common currency in one data set do not even appear in the other data set; and, even for the country pairs that do appear in both data

\footnotetext{
7 A likelihood ratio test easily rejects the hypothesis that the restrictions do not lead to statistically different results.

8 As suggested by Mátyás (1998) and Egger (2000), we tested whether the factors omitted from the pooled cross-section are random (uncorrelated with the independent variables) rather than fixed (correlated with the independent variables). A Hausman test easily rejects the random effects model. Given the discussion in Egger (2000) of the reasons why the fixed effects model is preferred a priori, this is not surprising.

9 The lower and upper bounds of the 95 percent confidence interval are that a common currency will lead countries to trade, respectively, 24 percent and 193 percent as much with each other.
} 
sets, the data sets often disagree on whether the countries had a common currency. For example, of the 85 country pairs in the Rose-Glick data set that are described as having shared a currency in 1975, only 37 (44 percent) even appear in Rose's original data set, and 15 (41 percent) of these are indicated as having different currencies. Also, of the 52 country pairs in Rose's original data set that are noted to have shared a currency in 1975, only 26 (50 percent) also appear in the Rose-Glick data set, 5 of which (19 percent) are indicated as having different currencies.

\section{CONCLUSIONS}

Although economists have long considered exchange rate stability and common-currency arrangements to provide for enhanced trading opportunities, very little empirical support for this notion has been uncovered over the years. Rose's estimates of the trade-creating effects of common currencies are so provocative because they depart so dramatically from the dearth of evidence supporting this widely held belief.

Our results suggest, however, that the evidence is much weaker than indicated by Rose's estimates; we conclude that Rose's results are not robust with respect to a general specification of time-invariant determinants of trade volume. Although the robustness question may appear to have been settled by Rose's impressive array of alternative specifications, our results indicate otherwise. In short, Rose's remarkable finding that a common-currency arrangement triples the volume of trade is due to estimation bias arising from omitted or misspecified variables that are correlated with trade volume and with the likelihood that countries use a common currency.

Using three different subsets of Rose's data to estimate a generalized fixed-effects model, our point estimates indicate that common-currency arrangements are associated with reduced trade. Using the data sets with longer intervals between observations, these results are even statistically significant. The fact that the evidence supporting trade-reducing effects of a currency union strengthens with the lengthening of the interval may simply be an artifact of the paucity of time-series information in the data set. With such a limited number of regime switches represented in the data, it may not be possible for the gravity approach to answer the key question of what happens to trade between two countries after they adopt a common currency. ${ }^{10}$
Our results should not be interpreted literally as demonstrating that a common currency will lead to a much lower volume of trade, particularly in light of the findings of Glick and Rose (2001). Indeed, such a result may strain credulity as much as Rose's finding of a tripling of trade. At the very least, though, one should be cautious about drawing any broad conclusions about the effects of common currencies on trade given that such a wide range of values can be estimated using this data set, and that the opposite sign can be obtained using a different and equally reasonable data set.

\section{REFERENCES}

Bacchetta, Philippe and van Wincoop, Eric. "Does ExchangeRate Stability Increase Trade and Welfare?" American Economic Review, December 2000, 90(5), pp. 1093-109.

Bayoumi, Tamim and Eichengreen, Barry. "Is Regionalism Simply a Diversion? Evidence from the Evolution of the EC and EFTA," in T. Ito and A. O. Krueger, eds., Regionalism Versus Multilateral Trade Arrangements. Chicago: University of Chicago Press, 1997.

Belanger, Denis; Gutierrez, Sylvia and Raynauld, Jacques. "The Impact of Exchange Rate Variability on Trade Flows: Further Results on Sectoral U.S. Imports from Canada." North American Journal of Economics and Finance, Spring 1992, pp. 888-92.

Brada, Josef C. and Mendéz, José A. "Exchange Rate Risk, Exchange Rate Regime and the Volume of International Trade." Kyklos, 1988, 41(2), pp. 263-80.

Cheng, I-Hui and Wall, Howard J. "Controlling for Heterogeneity in Gravity Models of Trade.” Working Paper 99 010B, Federal Reserve Bank of St. Louis, March 2001.

Côté, Agathe. "Exchange Rate Volatility and Trade: A Survey." Working Paper 94-5, Bank of Canada, May 1994.

De Grauwe, Paul. "Exchange Rate Variability and the Slowdown in Growth of International Trade." International Monetary Fund Staff Papers, March 1988, pp. 63-84.

Egger, Peter. "A Note on the Proper Econometric Specification of the Gravity Equation.” Economics Letters, January 2000, 66(1), pp. 25-31.

\footnotetext{
${ }^{10}$ Our results and conclusions are similar to those of Persson (2001), who applies a novel "matching approach" to estimate a "treatment effect" (a methodology with its roots in medical research) from the Rose data set.
} 
European Commission. "Practical Arrangements for the Introduction of the Single Currency." Green Paper, May 1995.

Frankel, Jeffrey A. and Rose, Andrew K. "Estimating the Effects of Currency Unions on Trade and Output." Working Paper No. 7857, National Bureau of Economic Research, August 2000.

Frankel, Jeffrey A. and Wei, Shang-Jin. "Trade Blocs and Currency Blocs” [NBER Working Paper No. 4335], in Guillermo de la Dehaza, Alberto Giovannini, and Richard Portes, eds., The Monetary Future of Europe. London: Centre for Economic Policy Research, 1993.

Glick, Reuven and Rose, Andrew K. "Does a Currency Union Affect Trade? The Time Series Evidence." Working Paper No. 8396, National Bureau of Economic Research, 2001.

Greene, William H. Econometric Analysis. Hemel Hempstead, UK: Prentice-Hall, 1999.

Hsiao, Cheng. Analysis of Panel Data. New York: Cambridge University Press, 1986.

Mátyás, László. "Proper Econometric Specification of the Gravity Model.” The World Economy, May 1997, 20(3), pp. 363-68.

"The Gravity Model: Some Econometric
Considerations." The World Economy, May 1998, 21(3), pp. 397-401.

Persson, Torsten. "Currency Unions and Trade: How Large Is the Treatment Effect?" Presented at the Economic Policy panel meeting in Stockholm, 6-7 April 2001, forthcoming in Economic Policy: A European Forum.

Plane, David A. "Migration Space: Doubly Constrained Gravity Model Mapping of Relative Interstate Separation." Annals of the Association of American Geographers, 1984, 74(2), pp. 244-56.

Rose, Andrew K. "Currency Unions and Trade: The Effect Is Large." Presented at the Economic Policy panel meeting in Stockholm, 6-7 April 2001.

"One Money, One Market: The Effect of Common Currencies on Trade." Economic Policy, April 2000, 15(30), pp. 7-46

and Engel, Charles. "Currency Unions and International Integration.” Working Paper No. 7872, National Bureau of Economic Research, September 2000.

and van Wincoop, Eric. "National Money as a Barrier to International Trade: The Real Case for Currency Union." American Economic Review, May 2001, 91(2), pp. 386-90. 
REVIEW

46 SEPTEMBER/OCTOBER 2001 